\title{
Flumazenil-induced Ballism
}

\begin{abstract}
Flumazenil, an imidazobenzodiazepine, is the first benzodiazepine antagonist and is being used to reverse the adverse pharmacological effects of benzodiazepine. There have been a few reports on the central nevous system side effects with its use. We report a patient with generalized ballism following administration of flumazenil. The mechanism through which flumazenil induced this symptom is unknown. It is conceivable that flumazenil may antagonize the GABA-benzodiazepine receptor complex and induce dopamine hypersensitivity, thus induce dyskinesic symptoms.
\end{abstract}

Key Words : Ballism; Flumazenil; GABA; Dopamine

\author{
Joong-Seok Kim, Seok-Bum Ko, \\ Yeong-Bin Choi, Kwang-Soo Lee \\ Department of Neurology, College of Medicine \\ The Catholic University of Korea, Seoul, Korea \\ Received: 15 March 2002 \\ Accepted : 15 May 2002 \\ Address for correspondence \\ Kwang-Soo Lee, M.D. \\ Department of Neurology, Kangnam St. Mary's \\ Hospital, 505 Banpo-dong, Seocho-gu, Seoul \\ 137-701, Korea \\ Tel : +82.2-590-2720, Fax : +82.2-599-9686 \\ E-mail : ks1007@cmc.cuk.ac.kr
}

\section{INTRODUCTION}

Flumazenil, an imidazobenzodiazepine, is the first benzodiazepine antagonist and is being used to reverse the adverse pharmacological effects of benzodiazepine. Other potential indications include hepatic encephalopathy, and other forms of coma (1). Flumazenil is a relative safe drug, with rare central nevous system (CNS) side effects, such as seizure, agitation and anxiety (2-4).

We report a case of ballistic movements that developed following the administration of flumazenil.

\section{CASE REPORT}

A 58-yr-old woman was found suffering from drowsiness and was transported to the emergency room. The patient had been treated with hemodialysis for chronic renal failure for the previous $10 \mathrm{yr}$. Her medication included $100 \mathrm{mg}$ aspirin, $10 \mathrm{mg}$ baclofen, and $5 \mathrm{mg}$ amitriptyline hydrochloride. She had never been on any neuroleptic or dopaminergic drugs and there was no past history of neurological disease.

On admission, she was confused, disoriented and drowsy, with a blood pressure of $120 / 90 \mathrm{mmHg}$, a regular heart beat of 96 beats $/ \mathrm{min}$, and a temperature of $36.8^{\circ} \mathrm{C}$. Physical examination did not demonstrate any pathologic findings. Neurologic findings were as follows: slightly dilated pupils, responsive to light, normal corneal, oculocephalic, and gag reflexes, decreased deep tendon reflexes, and symmetrical muscle flaccidity.

Laboratory tests included a sodium level of $141 \mathrm{mEq} / \mathrm{L}$, potassium $4.1 \mathrm{mEq} / \mathrm{L}$, creatinine $3.1 \mathrm{mg} / \mathrm{dL}$, blood urea nitrogen $37.3 \mathrm{mg} / \mathrm{dL}$, glucose $131 \mathrm{mg} / \mathrm{dL}, \mathrm{HbA1C} 6.2 \%$, white blood cell count $8,700 / \mu \mathrm{L}$, hemoglobin $13.1 \mathrm{~g} / \mathrm{dL}$, platelet count $313,000 / \mu \mathrm{L}$, and normal thyroid function. A brain MRI obtained on admission did not demonstrate any abnormality.

To diagnose and treat unexplained decreased mentality, intravenous flumazenil was administered in increments of $0.25 \mathrm{mg} / \mathrm{min}$. The patient regained full consciousness following a total dose of $1.0 \mathrm{mg}$ of flumazenil. One hour later, the patient developed ballistic movements of the proximal portion of the upper and lower limbs. The movements could be described as flexion/extension writhing movements of her limbs and grimacing of her face. These movements disappeared when she was asleep. On neurological examination, the patient was found to be alert and attentive. The cranial nerves were normal. There was no evidence of pyramidal disturbance. Power was full in all muscle groups. There was no abnormal subjective or objective sensory disturbance. Deep tendon reflexes were symmetric and normoactive and both plantar were flexor. All drugs were discontinued and her symptoms resolved within 3 days.

\section{DISCUSSION}

Experimental chorea models can be produced by injecting a $\gamma$-aminobutylic acid (GABA) antagonist into the external pallidum (GPe) or subthalamic nucleus (STN) $(5,6)$. The interruption of GABAergic transmission from the striatum to the GPe would lead to an abnormally increased GPe neu- 
ronal activity, which exerts an inhibitory action upon the STN (7). Increased STN inhibition would result in the loss of its control on the internal pallidum (GPi). Besides excitatory STN inputs (8), the GPi neurons also receive inhibitory afferent inputs directly from the striatum. The imbalance between the indirect excitatory and direct inhibitory pathways would ultimately lead to a disinhibition of the motor thalamus.

Benzodiazepines exert their main action on the central nevous system primarily by an enhancement of GABAergic synaptic transmission (9). These effects are mediated by the interaction of benzodiazepines with specific neuronal membrane proteins, the benzodiazepine receptors, which are localized, at least in part, in the GABAergic synapses (10). These GABAmimetic activities have been used effectively in the treatment of acquired and non-acquired chorea/bal$\operatorname{lism}(11)$.

Flumazenil selectively antagonizes the central actions of benzodiazepines by competitive interaction at the GABAbenzodiazepine receptor level. In addition, animal studies have shown that flumazenil can influence dopamine metabolism in the central nervous system. Flumazenil has been shown to increase the extracellular dopamine of mesolimbic dopaminergic neuron following repeated administration of benzodiazepine receptor partial agonists. Therefore, the administration of flumazenil may increase dopamine availability, in turn increasing dopamine receptor sensitivity (13).

The occurrence of a ballistic movement in our patient following the administration of flumazenil suggests a possible relationship between flumazenil and ballism, although the mechanism is not known and the short half-life of flumazenil effect makes flumazenil-related ballism unlikely. Since the drug was completely eliminated from the body within 48-72 hr following infusion of flumazenil (1), the effect of flumazenil did correlate with the duration of the patient's symptom. A potential explanation is that flumazenil may antagonize the GABA-benzodiazepine receptor complex and/or induce dopamine hypersensitivity and, therefore, cause dyskinesic symptoms.

It is of course possible that this symptom may be unrelated to flumazenil. In addition, as previously reported (14), other drug such as baclofen cannot be ruled out in relation to this condition. However, the long-term use of this drug without specific side-effects makes baclofen-induced dyskinesia unlikely in our case.

In summary, the temporal relationship to the administration of flumazenil and the absence of a clear etiology on the MRI support the association between flumazenil and ballism, despite the fact that a cause-and-effect relationship cannot be clearly inferred.

\section{REFERENCES}

1. Whitwam JG, Amrein R. Pharmacology of flumazenil. Acta Anaesthesiol Scand 1995; 108: S3-14.

2. Spivey WH. Flumazenil and seizure. Analysis of 43 cases. Clin Ther 1992; 14: 292-305.

3. Amrein R, Leishman B, Bentzinger C, Roncari G. Flumazenil in benzodiazepine antagonism. Actions and clinical use in intoxications and anaesthesiology. Med Toxicol Adverse Drug Exp 1987; 2: 411-29.

4. Prischl F, Donner A, Grimm G, Smetana R, Hruby K. Value of flumazenil in benzodiazepine self-poisoning. Med Toxicol Adverse Drug Exp 1988; 3: 334-9.

5. Crossman AR, Mitchell IJ, Sambrook MA, Jackson A. Chorea and myoclonus in the monkey induced by gamma-aminobutyric acid antagonism in the lentiform complex. The site of drug action and a hypothesis for the neural mechanisms of chorea Brain 1988; 111: 1211-33.

6. Crossman AR, Sambrook MA, Jackson A. Experimental hemichoreal hemiballism in the monkey: studies on the intracerebral site of action in a drug-induced dyskinesia. Brain 1984; 107: 579-96.

7. Ohye C, Le Guyader C, Feger J. Response of subthalamic and pallidal neurons to striatal stimulation: an extracellular study on awake monkeys. Brain Res 1976; 111: 241-52.

8. Hamada I, DeLong MR. Excitotoxic acid lesions of the primate subthalamic nucleus result in reduced pallidal neuronal activity during active holding. J Neurophysiol 1992; 68: 1859-66.

9. Hawfely W, Pieri L, Polc P, Schaffner R. General pharmacology and neuropharmacology of benzodiazepine derivative. In: Handbook of Experimental Pharmacology, vol 55: Psychotropic agents, Part 2 (Hoffmeister F and Stille G eds.), Springer-Verlag, Berlin 13262.

10. Mohler H, Richards JG, Wu JY. Autoradiographic localization of benzodiazepine receptors in immunocytochemically identified GABAergic synapses. Proc Natl Acad Sci USA 1981; 78: 1935-8.

11. Becker RE, Lal H. Pharmacological approaches to treatment of hemiballism and hemichorea. Brain Res Bull 1983; 11: 187-9.

12. Sangameswaran L, de Blas AL, Demonstration of benzodiazepinelike molecules in the mammalian brain with a monoclonal antibody to benzodiazepines. Proc Natl Acad Sci USA 1985; 82: 5560-4.

13. Motzo C, Porceddu ML, Dazzi L, Sanna A, Serra M, Biggio G. Enhancement by flumazenil release in the nucleus accumbens of rat repeatedly exposed to diazepam or imidazenil. Psychopharmacology (Berl) 1997; 131: 34-9.

14. Ryan DM, Blumenthal FS. Baclofen-induced dyskinesia. Arch Phys Med Rehabil 1993; 74: 766-7. 